\title{
Light and electron microscopic studies of the 139A-H strain of scrapie passaged in hamsters
}

\author{
Pawel P. Liberski ${ }^{1}$, Agata Gajos ${ }^{2}$, Beata Sikorska ${ }^{1}$, Janusz Moryś ${ }^{3}$ \\ ${ }^{1}$ Department of Molecular Pathology and Neuropathology, Medical University of Lodz, Poland, ${ }^{2}$ Department of Extrapyramidal \\ Diseases, Medical University of Lodz, Poland, ${ }^{3}$ Department of Anatomy and Neurobiology, Medical University of Gdansk, Poland
}

\begin{abstract}
We report here the light and electron microscopic neuropathology of the 139A-H strain of scrapie passaged in Syrian golden hamsters. The general neuropathological picture consisted of the spongiform change and severe astrocytic gliosis. The topography of prion protein (PrP) was variable, the highest signal was observed in the CA2-molecular layer, CA1-pyramidal and entorhinal cortex. The electron microscopy consisted of: 1. Spongiform vacuoles - these are always membrane bound and contain secondary vacuoles (i.e. membrane-bound compartments or vesicles within vacuoles) and curled membraned fragments. 2. Tubulovesicular structures (TVS) - these are vesicular structures of approximate $27 \mathrm{~nm}$ in diameter within neuronal processes - i.e. axonal terminal or dendrites. TVS are smaller and of higher electron density than synaptic vesicles. The significance of TVS remains unknown. 3. Dystrophic neurites. Dendrites or axonal preterminals and terminals filled with electron-dense bodies, including small autophagic vacuoles. 4. Apoptotic cell nuclei. 5. "Whorls", concentric arrays of membranes were visible. A significance of those structures is unknown.
\end{abstract}

Key words: scrapie, electron microscopy, topography of lesion.

\section{Introduction}

We report here the light and electron microscopic neuropathology of the $139 \mathrm{~A}-\mathrm{H}$ strain of scrapie passaged in Syrian golden hamsters. Scrapie is a natural disease of sheep, goats and mouflons. It is a member of the group of transmissible spongiform encephalopathies or "prion diseases" $[28,29]$. Several experimental models in laboratory and transgenic animals have been described and several strains of the scrapie agent exist; the most widely experimentally used are the 263K (237sc) strains. The $139 \mathrm{~A}-\mathrm{H}$ strain is less widely used and thus deserves a more detailed description.

\section{Material and methods \\ The 139A-H strain of scrapie}

This strain was derived from the Scrapie Sheep Brain Pool (SSBP)-1 lineage [3,5]. Briefly, scrapie from a natural source was passaged through Cheviot sheep, Welsh Mountain sheep, goats, mice and led to the isolation of the "Chandler" scrapie strain [3]. The clone 139A strain was derived following the passage in hamsters [11] and this strain was made available to us by Dr. Richard I Carp, IBR, Staten Island, USA. Of interest, the distinct nature of the 139A-H strain was recently proved by the extended cell panel assay [26].

\section{Communicating author}

Pawel P. Liberski, MD, PhD, Department of Molecular Pathology and Neuropathology, Medical University of Lodz, 4 Kosciuszki St., 90-419 Lodz, Poland, e-mail: ppliber@csk.umed.lodz.pl 


\section{Electron microscopy}

Two hamsters in the terminal stage of $139 \mathrm{~A}-\mathrm{H}$ scrapie infection and control sham-inoculated hamsters at the same interval after inoculation were anaesthetized with ketamine. They were perfused by intracardiac injection with saline followed by $150 \mathrm{ml}$ of $1.25 \%$ glutaraldehyde and $1 \%$ paraformaldehyde prepared in cacodylate buffer $(\mathrm{pH} 7.4)$ and then by $50 \mathrm{ml}$ of $5 \%$ glutaraldehyde and $4 \%$ paraformaldehyde.

Perfused animal carcasses were held at $4^{\circ} \mathrm{C}$ for at least 2 hours, after which brains were removed and several $1-\mathrm{mm}^{3}$ samples were dissected under a binocular microscope from the parietal cortex, corpus callosum, CA2 region of the hippocampus, thalamus, cerebellum and brain stem. These samples were postfixed in 1\% osmium tetroxide for 1-2 hours, dehydrated through a series of graded ethanols and propylene oxide, and then embedded in Epon resin (Serva). Semi-thin sections were stained with toluidine blue, blocks trimmed, and ultrathin sections stained with lead citrate and uranyl ace-

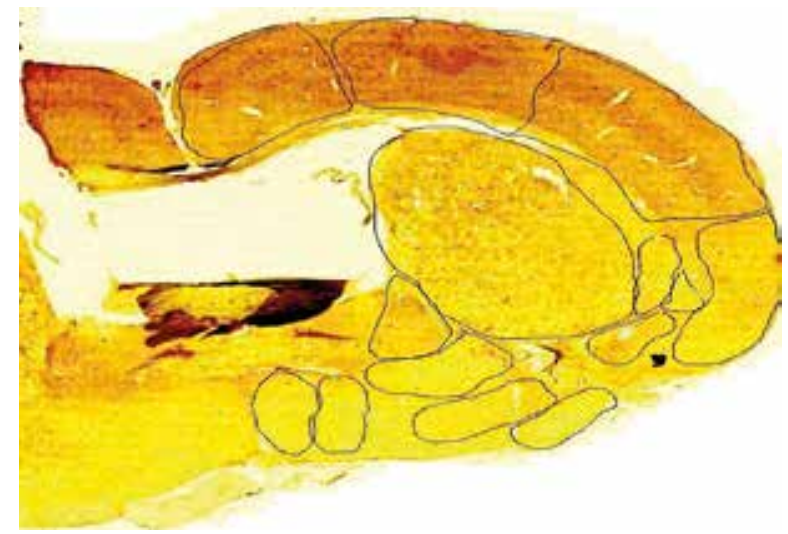

Fig. 1. The general view of the hamster brain as used for prion protein topography.

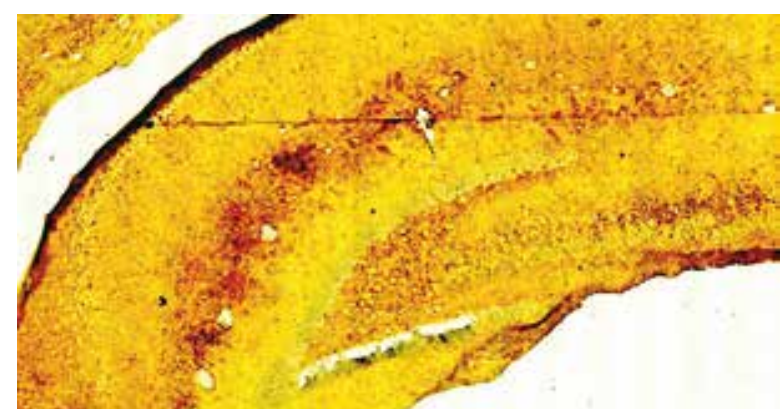

Fig. 2. A section through the hippocampus prepared for prion protein counting. tate. Sections were examined using a JEM $100 \mathrm{C}$ transmission electron microscope.

\section{Immunohistochemistry}

For immunohistochemical staining, 4\% formalinfixed and paraffin-embedded hamster brains were used. Paraffin-embedded tissue samples were cut into 4- $\mu \mathrm{m}$ sections and processed routinely. The following antibodies were used: prion protein (PrP) $6 \mathrm{H} 4$ (1 : 400, mouse monoclonal, Prionics, Switzerland), glial fibrillary acidic protein (GFAP) (1 : 750, rabbit polyclonal, Dako, Denmark). Antigens were unmasked by incubating the sections in $\mathrm{pH} 6.0$ citrate buffer using an autoclave (for PrP $6 \mathrm{H} 4$ only, 15 minutes, $121^{\circ} \mathrm{C}$ ) or using proteinase $\mathrm{K}$ digestion of sections for 5 minutes (for GFAP only). Additionally, tissue sections for PrP 6H4 staining were incubated in $98-100 \%$ formic acid. For the detection of antibodies the EnVision + System-HRP with DAB as a chromogen (K4007 for use with mouse primary antibody, K4011 for use with rabbit primary antibody; Dako) was used according to the instructions of the manufacturer. Nuclei were stained with hematoxylin.

\section{Analysis of PrP immunostaining}

The intensity of the immunostaining were quantified in a single hamster brain using the images obtained from the AxioScan.Z1 system (Zeiss, Germany) using the Zeiss Zen 2.3 (Blue Edition) Software. The image analysis program Zen 2.3 (Blue Edition; Zeiss, Germany) - for light microscope image reconstruction was used. The recognition of the regions of interest was achieved with the $4 \times$ magnification lens and measures of intensity of staining were performed at 20× magnification (Figs. 1 and 2). To extract background from the pictures in the studied test areas, the neighboring area without the brain tissue was measured and obtained results of the mean value of this area were subtracted from the intensity of brain tissue. Arbitrary units of immunostaining intensity were used for comparative analysis after correction for background intensity.

\section{Confocal laser microscopy}

Additionally, double immunofluorescent stainings for confocal laser microscopy were performed. For double immunofluorescence stainings, 4\% formalin fixed and paraffin-embedded hamster brains were used. Sections $(4 \mu \mathrm{m})$ were mounted on tissue slides 
and processed routinely. The sections were treated with a citrate antigen retrieval solution. The following antibodies were used and combinations were applied: prion protein PrP 6H4 (1: 400, Prionics, Switzerland), MAP-LC3 (1 : 2500, rabbit polyclonal, MBL). Tissue slides were mounted with Prolong Gold antifade reagent with DAPI (P36935, Molecular Probes). The staining results were evaluated with confocal laser-scanning microscope (Olympus FV1200, Japan). Serial optical sections in the $Z$ dimension were captured to allow for three-dimensional (3D) reconstruction. Imaris software version 8.1.2 (Bitplane $\mathrm{AG}^{\circledR}$, Zurich, Switzerland) was used to generate the 3D reconstructed images. Confocal Z-stacks comprising up to 20 images were reconstructed into 3D animations. Solid skinned cell-surface rendering was using Surface function. The filament tracer mode was used for detection of cell processes.

\section{Results}

The general neuropathological picture consisted of spongiform change (Fig. 3) and severe astrocytic gliosis (Fig. 4).

\section{Topography of PrP}

The topography of PrP deposits (in arbitrary units) is shown in Table I.

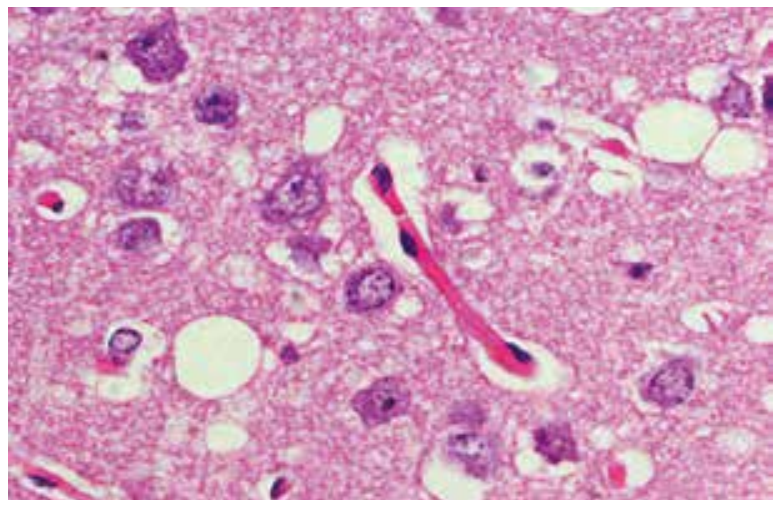

Fig. 3. A typical view of spongiform change. $H \& E, 40 x$.

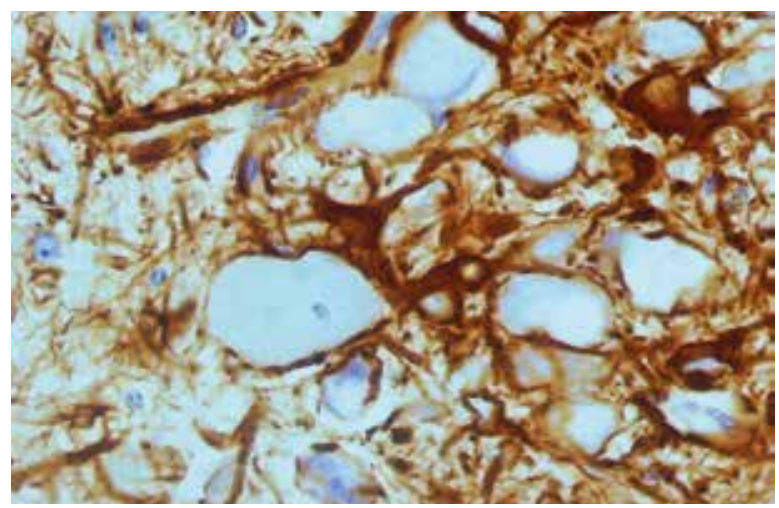

Fig. 4. A fragment of the brain area with severe astrocytic gliosis. GFAP immunostaining. Original magnification 40x.

Table I. The topography of PrP deposits (in arbitrary units)

\begin{tabular}{ll}
\hline Olfactory tubercle & 42.0 \\
\hline Medial preoptic area & 51.0 \\
\hline Lateral preoptic area & 52.0 \\
\hline Globus pallidus & 58.0 \\
\hline Barrel cortex & 66.0 \\
\hline Claustrum & 68.3 \\
\hline Endopiriform nucleus & 69.5 \\
\hline Nucleus accumbens & 69.6 \\
\hline Visual cortex & 70.2 \\
\hline Cortico-medial part of the amygdala & 71.9 \\
\hline Caudate-putamen & 72.9 \\
\hline Auditory cortex & 77.0 \\
\hline Piriform cortex & 78.1 \\
\hline Insular cortex & 78.7 \\
\hline CA3-piramidal layer + molecular & 78.8 \\
\hline Septum & 79.3 \\
\hline CA2-molecular layer & 82.0 \\
\hline CA1-pyramidal & 82.6 \\
\hline Entorhinal cortex & 83.3
\end{tabular}

\begin{tabular}{lc}
\hline CA3-molecular layer & 86.0 \\
\hline Temporal cortex & 86.8 \\
\hline Somatosensory cortex & 87.5 \\
\hline Auditory cortex & 87.9 \\
\hline Central nucleus of amygdala & 88.4 \\
\hline DG-granular layer & 88.6 \\
\hline Cingular cortex & 89.6 \\
\hline Motor cortex & 90.2 \\
\hline DG-hilus & 91.0 \\
\hline CA2-pyramidal molecular & 94.9 \\
\hline CA1-molecular layer & 98.9 \\
\hline Substantia nigra & 99.5 \\
\hline Pretectum & 100.1 \\
\hline Basolateral complex of the amygdala & 101.8 \\
\hline Dorsal lateral geniculate body & 104.0 \\
\hline Parietal cortex & 105.7 \\
\hline Ventral posteromedial thalamus & 109.4 \\
\hline Lateral geniculate body & 121.3 \\
\hline
\end{tabular}




\section{Electron microscopy}

Spongiform vacuoles (Fig. 5) - these are always membrane bound and contain secondary vacuoles (i.e. membrane-bound compartments or vesicles within vacuoles) and curled membraned fragments.

Tubulovesicular structures (TVS) (Fig. 6) - these are vesicular structures of approximate $27 \mathrm{~nm}$ in

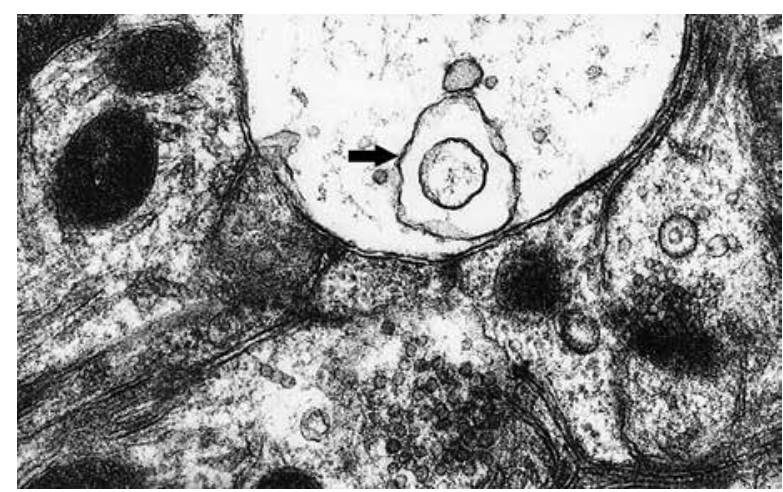

Fig. 5. A typical spongiform vacuole. Note secondary chamber (arrow), original magnification, 8300x.

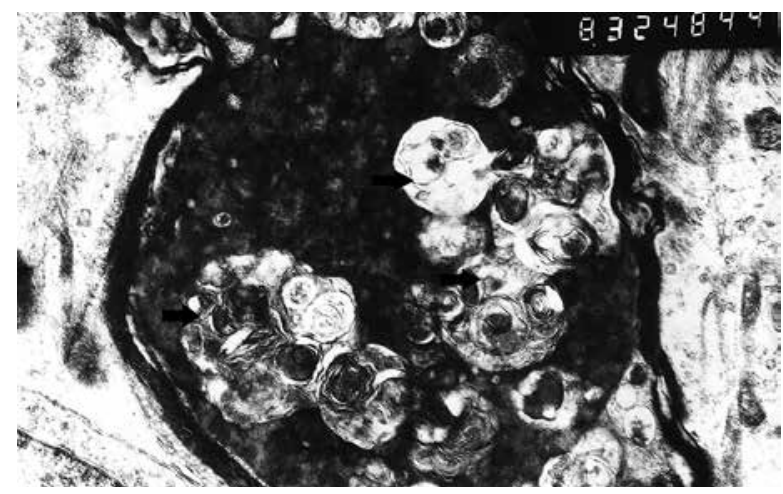

Fig. 7. A dystrophic neurite filled with autophagic vacuoles (arrows), original magnification, 8300x.

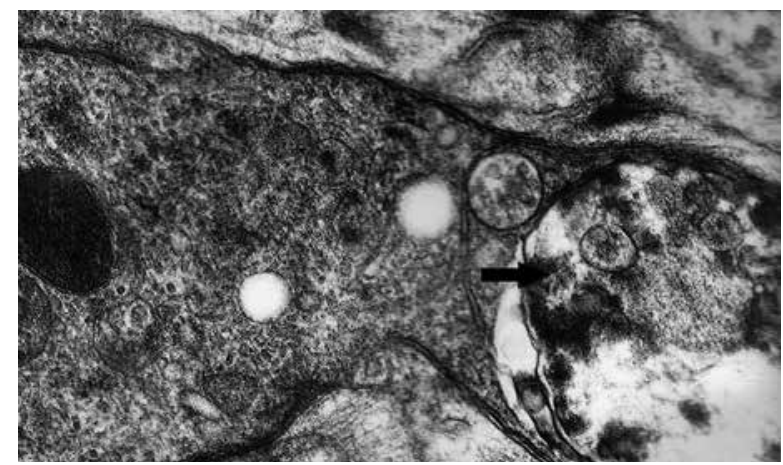

Fig. 9. A longitudinal section through the axon showing a large autophagic vacuole (arrow), original magnification, $20000 x$. diameter within neuronal processes - i.e. axonal terminal or dendrites. TVS are smaller and of higher electron density than synaptic vesicles. The significance of TVS remains unknown.

Dystrophic neurites (Figs. 7-9). Dendrites or axonal preterminals and terminals filled with electron-dense bodies, including small autophagic vacuoles.

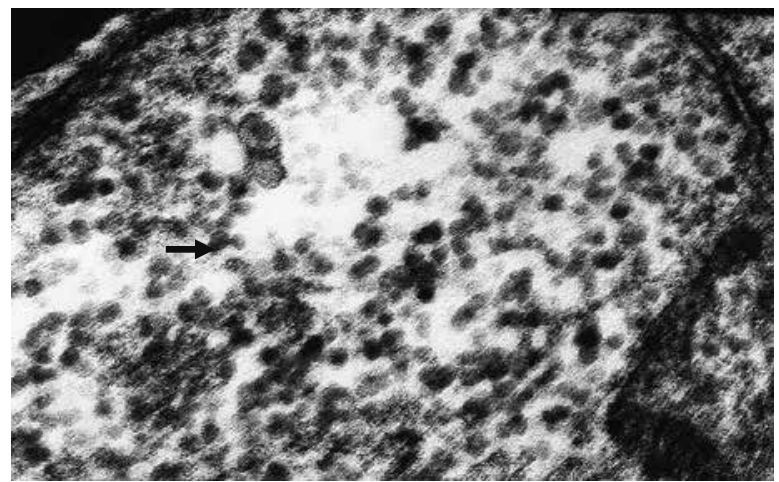

Fig. 6. Large magnification of tubulovesicular structures, original magnification, 50 000x.

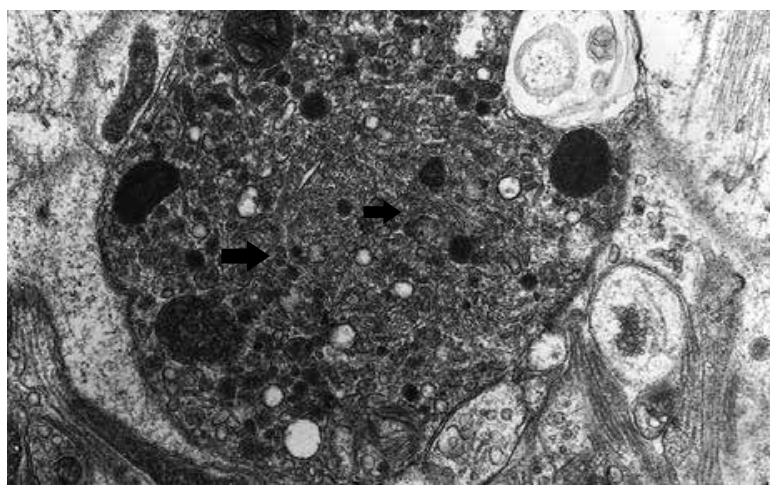

Fig. 8. A dystrophic neurite filled with autophagic vacuoles (arrows), original magnification, 8300x.

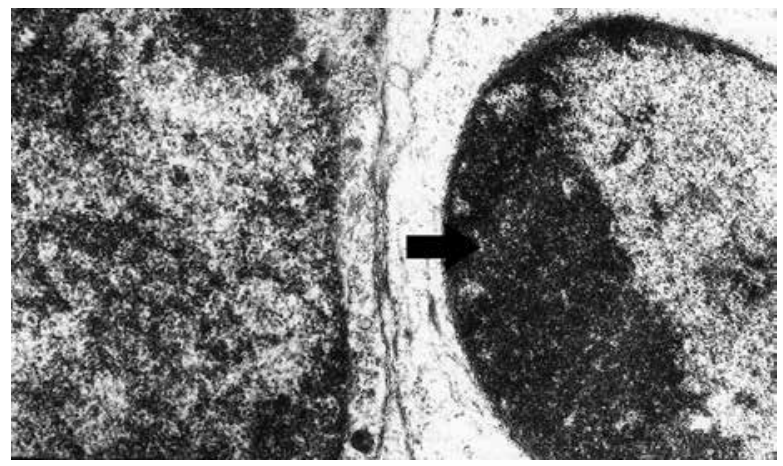

Fig. 10. A typical apoptotic nucleus (arrow), original magnification, 8300×. 
Apoptotic cell nuclei (Fig. 10).

"Whorls", concentric arrays of membranes were visible. A significance of those structures is unknown (Figs. 11-13).

\section{Confocal laser microscopy}

Double immunofluorescence stainings showed dot-like immunoreactivity of microtubule-associated protein (LC3) in the cell bodies while axons more often showed a fibrillar pattern. Interestingly, some neuronal processes showed only the neurofilament protein and LC3 positive structures were depleted of NFP immunoreactivity (Fig. 14).

\section{Discussion}

We characterized here the 139A-H scrapie strain using electron microscopy and immunohistochemis-

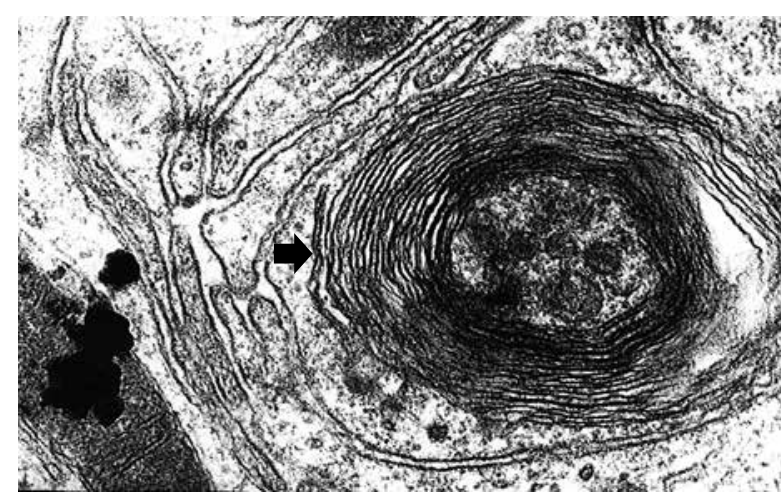

Fig. 11. A concentric array of membranes of unknown significance. A dystrophic neurite filled with autophagic vacuoles (arrows), original magnification, $20000 x$.

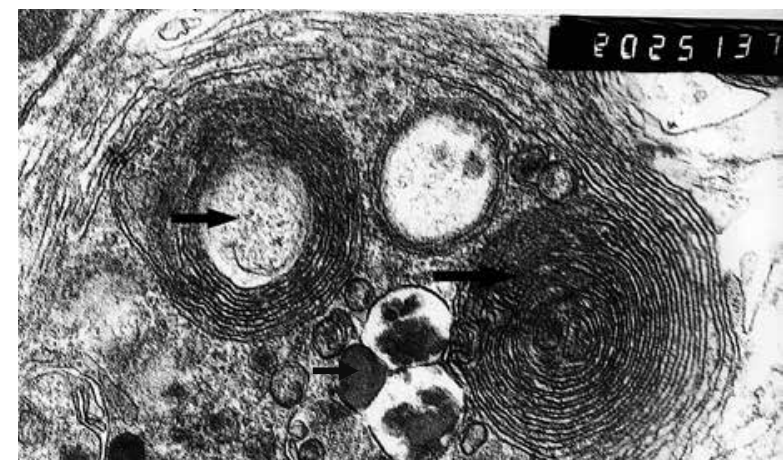

Fig. 13. A cytoplasm of a dystrophic neurite containing both autophagic vacuoles (thin arrow) and "whorls" (thick arrows), original magnification, $20000 \times$. try. The topography of deposition of $\operatorname{PrPSc}$ revealed marked differences from region to region; the highest signal was observed in the CA2-molecular layer, CA1-pyramidal and entorhinal cortex. There are no data available to make a comparison [31]. The electron microscopy revealed extensive autophagy and, to a lesser degree, apoptosis.

\section{Cell death in prion diseases}

Data on autophagy in TSEs are scanty. Our initial experimental approach using the hamsters-adapted $263 \mathrm{~K}$ or $22 \mathrm{C}-\mathrm{H}$ strains of scrapie $[14,19,20]$ was subsequently extended by studies of human brain biopsies from patients with sporadic CJD, variant CJD, and FFI [21] and mice infected with Gerstmann-Sträussler-Scheinker disease [18]. Autophagic vacuoles are defined as areas of the cytoplasm sequestered with-

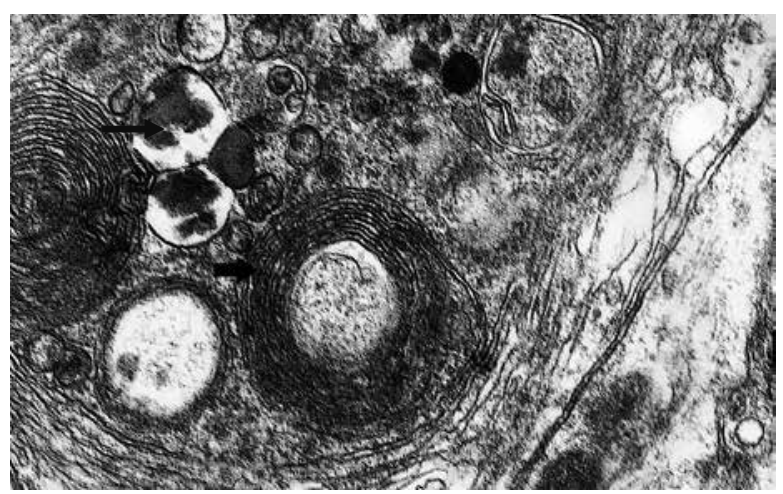

Fig. 12. A cytoplasm of a dystrophic neurite containing both autophagic vacuoles (thin arrow) and "whorls" (thick arrow), original magnification, $20000 \times$.

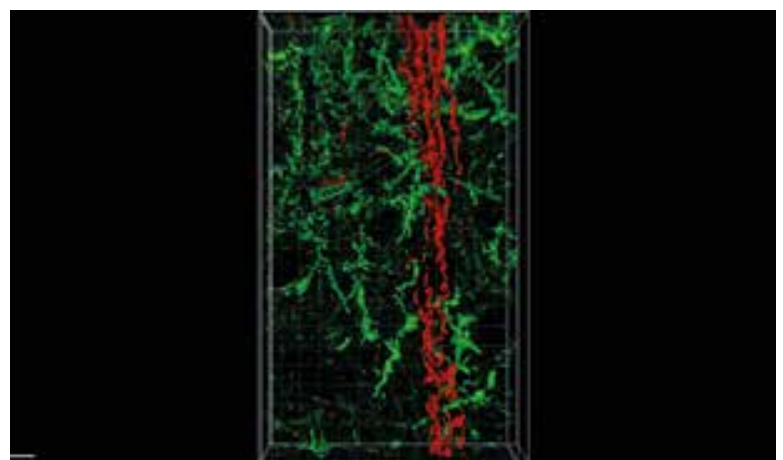

Fig. 14. Immunoreactivity of MAP LC3 (red) and neurofilaments (green) in scrapie 139A-Ha infected hamster, 3D reconstruction, confocal laser microscopy, magnification 600×, digital zoom 1.8×. 
in double or multiple membranes (phagophores) of unknown origin [12]. In a classic Lampert [13] paper, a description of "dystrophic", "regenerative" and "degenerative" neuritis was provided based on their appearance on transmission electron microscopy. Subsequently, it appeared that the criteria for separation into those 3 classes of neurites are not that clear and we used the term "dystrophic neurites" to cover all classes of altered neuronal branches that accumulate, irrespective of the cause, diverse subcellular organelles. Recently, Nixon et al. [2,25] interpreted many of those dense-bodies as small autophagic vacuoles. That dystrophic neurites in prion diseases are caused by the impairment of axonal transport was suggested many years ago by Gajdusek [6] and we showed it experimentally in experimental scrapie $[7,23,24]$, BSE [22] CJD [16] and GSS [18] and, finally in chronic wasting disease [8]. Collectively, dystrophic neurites form a constant alteration in the TSE-affected brains. However, the mechanism(s) of their formation may only be speculated upon. We and others have suggested that neurons degenerate in prion diseases by autophagy $[1,9,14,15,17,18,27,32]$, a process involving the removal of misfolded proteins and certain organelles, like mitochondria $[4,10,30]$, and it was even suggested that spongiform vacuoles derived from giant autophagic vacuoles. Furthermore, the different dense bodies encountered in dystrophic neurites are in fact, autophagic vacuoles. In addition, multivesicular bodies are an ultrastructural hallmark of prion diseases [20].

\section{Confocal laser microscopy}

Dot-like immunoreactivity of LC3 is considered a marker of autophagy. In confocal laser microscopy of 139A-HA scrapie infected hamster brains, autophagic vacuoles were observed in some cell bodies, but most long neuronal processes showed mainly a fibrillar pattern of immunoexpression which is typical for undamaged axons. These findings are in accordance with the ultrastructural observation of autophagy in cell bodies and axonal terminals.

\section{Disclosure}

The authors report no conflict of interest.

\section{References}

1. Boellaard JW, Kao M, Schlote W, Diringer H. Neuronal autophagy in experimental scrapie. Acta Neuropathol 1991; 82: 225-228.
2. Bordi M, Berg MJ, Mohan PS, Peterhoff CM, Alldred MJ, Che S, Ginsberg SD, Nixon RA. Autophagy flux in CA1 neurons of Alzheimer hippocampus: Increased induction overburdens failing lysosomes to propel neuritic dystrophy. Autophagy 2016; 12: 2467-2483.

3. Chandler RL. Encephalopathy in mice produced by inoculation with scrapie brain material. Lancet 1961; 1: 1378-1379.

4. Ciechanover A, Kwon YT. Degradation of misfolded proteins in neurodegenerative diseases: therapeutic targets and strategies. Exp Mol Med 2015; 47: e147.

5. Dickinson AG. Scrapie in sheep and goats. In: Kimberlin RH (ed.). Slow Virus Diseases of Animals and Man, North-Holland Publ. Comp., Amsterdam, 1976, pp. 209-241.

6. Gajdusek DC. Hypothesis: interference with axonal transport of neurofilaments as a common patbhogenetic mechanism in certain diseases of the central nervous system. N Engl J Med 1985; 209: 714-719.

7. Gibson PH, Liberski PP. An electron and light microscopic study of the numbers of dystrophic neurites and vacuoles in the hippocampus of mice infected intracerebrally with scrapie. Acta Neuropathol 1987; 73: 379-382.

8. Guiroy DC, Liberski PP, Williams ES, Gajdusek DC. Electron microscopic findings in brain of Rocky Mountain elk with chronic wasting disease. Folia Neuropathol 1994; 32: 171-173.

9. Heiseke A, Aguib Y, Schatzl HM. Autophagy, prion infection and their mutual interactions. Curr Issues Mol Biol 2010; 12: 87-97.

10. Joshi-Barr S, Bett C, Chiang WC, Trejo M, Goebel HH, Sikorska B, Liberski P, Raeber A, Lin JH, Masliah E, Sigurdson CJ. De novo prion aggregates trigger autophagy in skeletal muscle. J Virol 2014; 88: 2071-2082.

11. Kimberlin RH, Cole S, Walker CA. Temporary and permanent modifications to a single strain of mouse scrapie on transmission to rats and hamsters. J Gen Virol 1987; 68 (Pt 7): 1875-1881.

12. Klionsky DJ, Abdelmohsen K, Abe A, Abedin MJ, Abeliovich H, Acevedo Arozena A, Adachi H, Adams CM, [...], Liberski PP, [...], Sikorska B, et al. Guidelines for the use and interpretation of assays for monitoring autophagy (3rd edition). Autophagy 2016; 12: 1-222.

13. Lampert PW. A comparative electron microscopic study of reactive, degenerating, regenerating, and dystrophic axons. J Neuropathol Exp Neurol 1967; 26: 345-368.

14. Liberski PP, Brown DR, Sikorska B, Caughey B, Brown P. Cell death and autophagy in prion diseases (transmissible spongiform encephalopathies). Folia Neuropathol 2008; 46: 1-25.

15. Liberski PP, Budka H. Ultrastructural pathology of Gerstmann-Sträussler-Scheinker disease. Ultrastruct Pathol 1995; 19: 23-36.

16. Liberski PP1, Budka H, Yanagihara R, Gajdusek DC. Neuroaxonal dystrophy in experimental Creutzfeldt-Jakob disease: electron microscopical and immunohistochemical demonstration of neurofilament accumulations within affected neurites. J Comp Pathol 1995; 112: 243-255.

17. Liberski PP, Gajdusek DC, Brown P. How do neurons degenerate in prion diseases or transmissible spongiform encephalopathies (TSEs): neuronal autophagy revisited. Acta Neurobiol Exp (Wars) 2002; 62: 141-147. 
18. Liberski PP, Gajos A, Bogucki A. Robust autophagy in optic nerves of experimental Creutzfeldt-Jakob disease and Gerstmann-Sträussler-Scheinker disease. Folia Neuropathol 2017; 55: 289-294.

19. Liberski PP, Sikorska B, Bratosiewicz-Wasik J, Gajdusek DC, Brown P. Neuronal cell death in transmissible spongiform encephalopathies (prion diseases) revisited: from apoptosis to autophagy. Int J Biochem Cell Biol 2004; 36: 2473-2490.

20. Liberski PP, Sikorska B, Gibson P, Brown P. Autophagy contributes to widespread neuronal degeneration in hamsters infected with the Echigo-1 strain of Creutzfeldt-Jakob disease and mice infected with the Fujisaki strain of Gerstmann-Sträussler-Scheinker (GSS) syndrome. Ultrastruct Pathol 2011; 35: 31-36.

21. Liberski PP, Sikorska B, Hauw JJ, Kopp N, Streichenberger N, Giraud P, Boellaard J, Budka H, Kovacs GG, Ironside J, Brown P. Ultrastructural characteristics (or evaluation) of CreutzfeldtJakob disease and other human transmissible spongiform encephalopathies or prion diseases. Ultrastruct Pathol 2010; 34: 351-361.

22. Liberski PP, Sikorska B, Wells GA, Hawkins SA, Dawson M, Simmons MM. Ultrastructural findings in pigs experimentally infected with bovine spongiform encephalopathy agent. Folia Neuropathol 2012; 50: 89-98.

23. Liberski PP, Yanagihara R, Gibbs CJ Jr, Gajdusek DC. Scrapie as a model for neuroaxonal dystrophy: ultrastructural studies. Exp Neurol 1989; 106: 133-141.

24. Liberski PP, Yanagihara R, Wells GA, Gibbs CJ Jr, Gajdusek DC. Ultrastructural pathology of axons and myelin in experimental scrapie in hamsters and bovine spongiform encephalopathy in cattle and a comparison with the panencephalopathic type of Creutzfeldt-Jakob disease. J Comp Pathol 1992; 106: 383-398.

25. Nixon RA. The role of autophagy in neurodegenerative disease. Nat Med 2013; 19: 983-997.

26. Oelschlegel AM, Fallahi M, Ortiz-Umpierre S, Weissmann C. The extended cell panel assay characterizes the relationship of prion strains RML, 79A, and 139A and reveals conversion of 139A to 79A-like prions in cell culture. J Virol 2012; 86: 5297-5303.

27. Onodera T. Dual role of cellular prion protein in normal host and Alzheimer's disease. Proc Jpn Acad Ser B Phys Biol Sci 2017; 93: 155-173.

28. Prusiner SB. Biology and genetics of prions causing neurodegeneration. Annu Rev Genet 2013; 47: 601-623.

29. Scheckel C, Aguzzi A. Prions, prionoids and protein misfolding disorders. Nat Rev Genet 2018; 19: 405-418.

30. Shah SZA, Zhao D, Hussain T, Sabir N, Yang L. Regulation of MicroRNAs-Mediated Autophagic Flux: A New Regulatory Avenue for Neurodegenerative Diseases With Focus on Prion Diseases. Front Aging Neurosci 2018; 10: 139.

31. Shi Q, Xiao K, Zhang BY, Zhang XM, Chen LN, Chen C, Gao C, Dong XP. Successive passaging of the scrapie strains, ME7-ha and 139A-ha, generated by the interspecies transmission of mouse-adapted strains into hamsters markedly shortens the incubation times, but maintains their molecular and pathological properties. Int J Mol Med 2015; 35: 1138-1146.

32. Shin HY, Oh JM, Kim YS. The Functional Role of Prion Protein (PrPC) on Autophagy. Pathogens 2013; 2: 436-445. 